\title{
Numerical modeling of a flat air solar collector fitted with obstacles
}

\author{
Mohammed Amine Amraoui ${ }^{1 *}$, and Fayssal Benosman ${ }^{1}$ \\ ${ }^{1}$ Faculty of Technology, Department of Mechanical Engineering, University Djillali LIABES Sidi-Bel-Abbès, BP 8922000 Sidi-Bel- \\ Abbès, Algeria
}

\begin{abstract}
The weakness of the solution of flat-air solar collectors in the absence of a turbulence promoter has led researchers to seek other means to improve the performance of the collector. to improve the heat exchange in the air stream from the flat solar collector to the air is the creation of baffles or obstacles to give the longest possible flow path and create a large possible turbulence network. In this article, we studied an air flow around an obstacle field in a flat air solar collector, using the Ansys CFX calculator software, we make a digital $3 \mathrm{D}$ similarity and we give results on the heat exchange in the flat air solar collector and the aim of this study is to show the effect of the obstacles for the fluid flow and the heat transfer in the fluid flow of the flat air solar collector.
\end{abstract}

\section{Introduction}

The improvement of the performances of the flat air solar collector is the interest of several researchers for that there are several works on the increase of the efficiency of the solar collector, I noted some work on this field of research.

The author MA Bernier and al [1] studied the air flow in a solar air collector, they made an experimental study to test two air flow rates with different gauge pressure for three possible cases of air passage in the soliare sensor, the efficiency was made by three inlet and outlet mass flow and the enthalpy equilibrium method, they concluded that it is necessary to standardize the inlet gauge when testing them.

In the study by Sari Hassoun Zakaria and al [2], is interested in improving the performance of a flat-air solar collector equipped with mini concentrators at the absorber level. A bibliographic study on previous work relating to flat air solar collectors enabled us to orient their research towards specific aspects still addressed in the literature. The aim of this work is to make a digital simulation of the flow of the air studied, the evolution of the outlet temperature of the sensor. The evolution of the temperature of the absorber is also determined.

The article of Ole Arborg [3] presents on the use of the solar plane collector with air, he gave several study which presents the importance of the solar collector to produce the heat, the author gave several results like the graph which shows the relation between the energy consumption of the fan and the flow of air flowing into the flat air soliare collector, Power consumption of the fan for a particular air flow and Power consumption in relation to the solar radiation used.
Andrei-Stelian Bejan and al [4] presents a study on flat air solar collectors for home heating, they gave several studies in this field, they gave several models of flat air solar collectors with glass and without glass, the authors have given a graph presenting Energy and temperature supplied by an opaque perforated collector in real conditions.

The work of T. Letz and al [5] concerns the study of the behavior of a flat air solar collector operating in a dynamic regime. A model based on solving heat balance equations by a nodal method has been established. The behavior of solar air collectors has been studied in natural sunlight and in artificial sunlight in order to better control the parameters on which the yield depends. It should be noted that this type of sensor, mounted on the roof, has a relatively high inertia which results in a low value of the efficiency of the sensor at the start of the day, and a higher value at the end of the day. While the air flow in the sensor and the inlet temperature have a great influence on the efficiency, on the other hand the inclination of the sensor and the illumination have little influence.

The authors Ioan Luminosu and al [6] have a study on air solar collector in romania, they studied the influence of flow on the efficiency of the solar collector, they concluded that the optimal flow is $\mathrm{mmm}$ and the use of photovoltaic systems Hybrid heaters good for the economic cost of energy where the electrical energy used to power the fans in addition to that this system can be used for any type of solar drying.

In the work of Zedairia Merouane and al [7] were interested in improving the thermal performance of a range of flat air solar collectors (single pass). A digital investigation was carried out to highlight the impact of

\footnotetext{
* Corresponding author: amraoui mohammedamine@yahoo.fr
} 
geometric parameters such as, the height of the channel, the distance between the glass and the absorber, the length and width of the sensor, and the thickness of the insulation on the thermal performance of flat air solar collectors. To do this, they developed a computer calculation program under the MATLAB environment, which allowed them to have several information on the evolution of all the parameters studied. Finally, representative curves were established to visualize these impacts which help to identify optimal values of the geometric parameters.

The air sensor studied in the article by S. Oudjedi and al [8] is a single-pass insulator between the absorber and the glass. An analysis of unsteady heat exchanges in such a sensor is presented. It is shown that in a quasistationary regime the heat balance equations of the sensor components cascade into a first-order ordinary differential equation, which alone governs the thermal behavior of the sensor. The solution of this differential equation is written as an explicit expression of the local temperature of the heat transfer fluid as a function of the time-varying solar flux. The influence of various parameters such as the inlet temperature of the fluid, its velocity and the height of the air flow channel on the thermal performance of the solar air collector is also studied.

In our model we made a numerical study on a flat air soliare sensor equipped with square obstacles, we gave the diagram of our model after we made the mesh of this model and then we gave results on the temperature distribution, the speed and the turbulence field and finally we presented graphs on the average Nuselt number, the average friction coefficient as a function of Reynolds number.

\section{Analysis and modelling}

\subsection{Problematic}

have made a flat air solar collector with square obstacles, the length of this collector is $900 \mathrm{~mm}$, the width is $500 \mathrm{~mm}$ and the height of the obstacles and the air stream is $25 \mathrm{~mm}$.

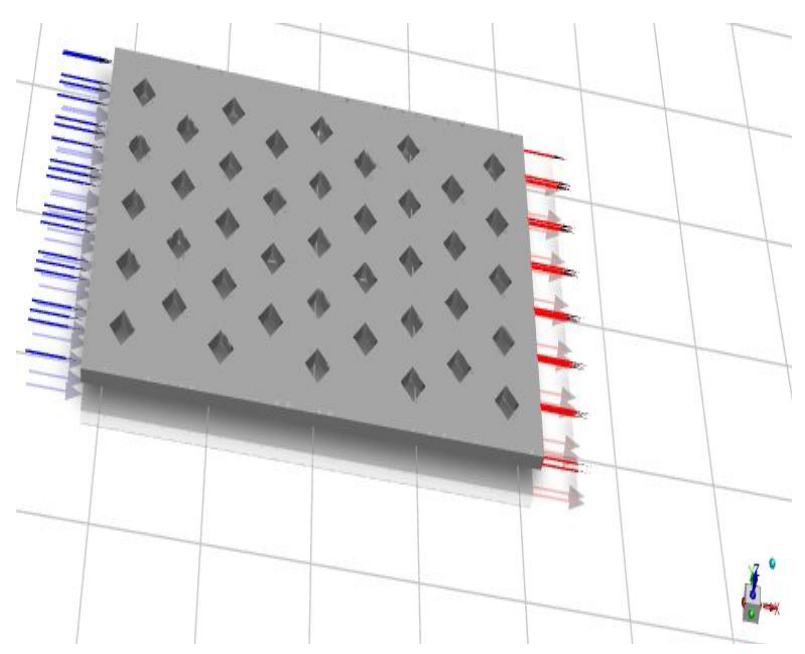

Fig. 1. Sketch for the solar collector

\subsubsection{The boundary conditions}

We used the k- $\varepsilon$ model for our air flow the flat air solar collector, to do this simulation we used the value of the input speed $\left(\mathrm{u}_{0}=0.02216 \mathrm{~m} / \mathrm{s}\right)$, the air temperature at the inlet $\mathrm{Te}=300 \mathrm{~K}$, the turbulent kinetic energy at inlet $\mathrm{k}=0.005 . \mathrm{U}_{0}^{2}=2.456 \cdot 10-6 \mathrm{~m}^{2} / \mathrm{s}^{2}$, the energy dissipation at inlet $\varepsilon=0.1 \cdot \mathrm{k}^{2}=6.03 \cdot 10-13 \mathrm{~m}^{2} / \mathrm{s}^{3}$, the temperature of the absorber: Tabs $=380 \mathrm{~K}$, the temperature of the insulation and the obstacles:Tiso $=340 \mathrm{~K}$ and the outlet pressure: Ps $=$ Patm.

we have validated our numerical results by the experimental results of abdelhafid [9], one notices that the results almost equal.

Table 1. Validation of results between experimental and CFD results [10].

\begin{tabular}{|c|c|c|}
\hline $\begin{array}{c}\text { Flow } \\
\mathrm{m}^{3} / \mathrm{hm}^{2}\end{array}$ & $\begin{array}{c}\mathrm{CFD} \\
\mathrm{T}\left({ }^{\circ} \mathrm{C}\right)\end{array}$ & $\begin{array}{c}\text { Experimental } \\
\mathrm{T}\left({ }^{\circ} \mathrm{C}\right)\end{array}$ \\
\hline $\mathrm{Q} 1=79.79$ & 53 & 50 \\
$\mathrm{Q} 2=76.32$ & 53 & 50 \\
\hline $\mathrm{Q} 3=74.01$ & 54 & 51 \\
\hline $\mathrm{Q} 4=69.96$ & 54 & 52.3 \\
\hline $\mathrm{Q} 5=64.76$ & 59 & 56 \\
\hline $\mathrm{Q} 6=58.97$ & 62 & 58 \\
\hline $\mathrm{Q} 7=42.79$ & 65 & 63 \\
\hline $\mathrm{Q} 8=37.58$ & 65 & 63 \\
\hline $\mathrm{Q} 9=23.71$ & 69 & 68 \\
\hline
\end{tabular}

\subsubsection{Governing equations}

- The Mass Conservation Equation:

The equation for conservation of mass, or continuity equation, can be written as follows:

$$
\nabla \cdot(\rho \vec{v})=0
$$

- Momentum Conservation Equations:

$$
\nabla \cdot(\rho \vec{v} \vec{v})=-\nabla p+\nabla(\overline{\bar{\tau}})+\rho \vec{g}
$$

$\rho \vec{g}$ The gravitational body force.

$\vec{g}$ : gravitational acceleration $(\mathrm{m} / \mathrm{s} 2)$

$\rho$ : density $(\mathrm{kg} / \mathrm{m} 3)$.

$p$ : the static pressure (pa).

$\vec{v}$ : overall velocity vector $(\mathrm{m} / \mathrm{s})$.

$\overline{\bar{\tau}}$ : the stress tensor (described below) (pa)

The stress tensor $\overline{\bar{\tau}}$ is given by 


$$
\overline{\bar{\tau}}=\mu\left[\left(\nabla \vec{v}+\nabla \vec{v}^{T}\right)-\frac{2}{3} \nabla \cdot \vec{v} I\right]
$$

The second term on the right hand side is the effect of volume dilation

The Energy Equation:

$$
\nabla \cdot(\vec{v}(\rho E+p))=\nabla \cdot\left(k_{\text {eff }} \cdot \nabla \mathrm{T}-\sum_{\mathrm{j}} \mathrm{h}_{\mathrm{j}} \cdot \overrightarrow{\mathrm{j}}_{\mathrm{j}}+\left(\overline{\bar{\tau}}_{\mathrm{eff}} \cdot \vec{v}\right)\right)
$$

The first three terms on the right-hand side of equation (4) represent energy transfer due to conduction, species diffusion, and viscous dissipation, respectively.

$$
k_{\mathrm{eff}}=k+\frac{c_{p} \mu_{t}}{P r_{t}}
$$

The default value of the turbulent Prandtl number is 0.85 .

$$
\begin{gathered}
E=h-\frac{p}{\rho}+\frac{v^{2}}{2} \\
h=\sum_{j} Y_{j} h_{j}+\frac{p}{\rho} \\
h_{j}=\int_{T_{r e f}}^{T} c_{p . j} d T
\end{gathered}
$$

$E$ : the total energy $(\mathrm{J})$.

$h$ : Sensible enthalpy (energy/mass).

$I$ : the unit tensor.

$\overrightarrow{\mathrm{j}}_{\mathrm{j}}: \mathrm{n}$ the diffusion flux of species $\mathrm{j}$.

$P r_{t}$ : the turbulent Prandtl numbers.

Where $T_{\text {ref }} 298.15 \mathrm{~K}$.

Transport Equations for the Standard k- $\varepsilon$ Model:

The turbulent kinetic energy, $\mathrm{k}$, and its turbulent eddy dissipation, $\varepsilon$, are obtained from the following transport equations:

$$
\frac{\partial}{\partial x_{i}}\left(\rho k u_{i}\right)=\frac{\partial}{\partial x_{j}}\left[\left(\mu+\frac{\mu_{t}}{\sigma_{k}}\right) \frac{\partial k}{\partial x_{j}}\right]+G_{k}-\rho_{\varepsilon}
$$

And

$\frac{\partial}{\partial x_{i}}\left(\rho \varepsilon u_{i}\right)=\frac{\partial}{\partial x_{j}}\left[\left(\mu+\frac{\mu_{t}}{\sigma_{\varepsilon}}\right) \frac{\partial \varepsilon}{\partial x_{j}}\right]+C_{1 \varepsilon} \frac{\varepsilon}{k} G_{k}-C_{2 \varepsilon} \rho \frac{\varepsilon^{2}}{K}$

$G_{k}$ : the generation of turbulence kinetic energy due to the mean velocity gradients.

Modeling the Turbulent Viscosity:

The turbulent (or eddy) viscosity, $\mu_{t}$, is computed by combining $\mathrm{k}$ and $\varepsilon$ as follows:

$$
\mu_{t}=\rho \cdot C_{\mu} \frac{k^{2}}{\varepsilon}
$$

Where $C_{\mu}$ is a constant.

Model Constants:

The model constants $C_{1 \varepsilon}, C_{2 \varepsilon}, C_{\mu}, \sigma_{k}$ and $\sigma_{\varepsilon}$ have the following default values:

$$
C_{1 \varepsilon}=1.44, C_{2 \varepsilon}=1.92, C_{\mu}=0.99, \sigma_{k}=1.0, \sigma_{\varepsilon}=1.3
$$

\subsubsection{Collector study}

A flat air solar collector transforms the solar radiation energy by a thermal energy absorbed by the heat transfer fluid "air"; therefore, a flow of air enters the flat air solar collector by a temperature and follows an $\mathrm{x}$ axis up to at the output of the solar collector by a temperature $T_{2}$.

$$
\varphi_{0} \cdot \text { l. } L=\rho \cdot c_{p} \cdot q_{v}\left(T_{2}-T_{1}\right)
$$

$\rho$ : average density of air $\rho=1.25 \mathrm{~kg} / \mathrm{m}^{3}$

$c_{p}$ : average mass heat of air $c_{p}=1000 \mathrm{j} /\left(\mathrm{kg}^{\circ} \mathrm{C}\right)$

$L$ : the length (along x) (m).

$\varphi_{0}$ : the solar flow is perpendicular to the collector $(\mathrm{W} / \mathrm{m} 2)$.

An air flow by abscissa $\mathrm{x}$ with an average temperature $\mathrm{T}$, we take an element of air $\mathrm{dx}$ we have:

Power received by the collector:

$$
\varphi_{0} . \ell . d x
$$

$\ell$ : the width of the flow $(\mathrm{m})$.

Power carried by the fluid:

$$
\rho \cdot c_{p} \cdot q_{v} \cdot d T=h . \ell \cdot d x\left(T_{p}-T\right)
$$

$h$ : the transfer coefficient between the absorbent wall and the fluid $(\mathrm{W} / \mathrm{m} 2)$.

$T_{p}$ : the temperature of the absorbent $q_{v}:$ the air flow

We present $h$ by the following equation:

$$
\frac{h \cdot d H}{\lambda}=N u
$$

$e \ll \ell$ so $d H=2 e$

$d H$ : hydraulic diameter of the section.

The power lost by conduction to the insulating part:

$$
\frac{\lambda_{i}}{E_{i}} \cdot \ell \cdot d x\left(T_{p}-T_{e}\right)
$$

$T_{e}$ : outside temperature (equal to ).

We will have a steady state:

$$
\begin{aligned}
& \rho \cdot c_{p} \cdot q_{v} \cdot d T=\frac{\lambda \cdot N u}{2 e} \cdot \ell \cdot d x\left(T_{p}-T\right)=\varphi_{0} \cdot \ell \cdot d x- \\
& \frac{\lambda_{i}}{E_{i}} \cdot \ell \cdot d x\left(T_{p}-T_{e}\right)
\end{aligned}
$$

we solve these equations so we eliminate $T_{p}$; at the end we conclude the differential equation:

$$
\frac{d T}{\varphi_{0}+\frac{\lambda_{i}}{E_{i}} \cdot\left(T_{e}-T\right)}=\frac{\ell \cdot d x}{\rho \cdot c_{p} \cdot q_{v}\left(1+\frac{\lambda_{i}}{E_{i}} \cdot \frac{2 e}{\lambda \cdot N u}\right)}
$$

Let's integrate this relationship between entry and exit:

$$
\begin{aligned}
& \int_{T_{e}}^{T_{2}} \frac{d \boldsymbol{T}}{\varphi_{0}+\frac{\lambda_{i}}{E_{i}} \cdot\left(T_{e}-T\right)}=\int_{0}^{L} \frac{\ell \cdot d x}{\rho \cdot c_{p} \cdot q_{v}\left(1+\frac{\lambda_{i}}{E_{i}} \cdot \frac{2 e}{\lambda \cdot N u}\right)} \\
& -\frac{E_{i}}{\lambda_{i}}\left[\ln \left(\varphi_{0}+\frac{\lambda_{i}}{E_{i}} \cdot\left(T_{e}-T\right)\right)\right]_{T_{e}}^{T_{2}}=\frac{\ell . L}{\rho \cdot c_{p} \cdot q_{v}\left(1+\frac{\lambda_{i}}{E_{i}} \cdot \frac{2 e}{\lambda \cdot N u}\right)}
\end{aligned}
$$


From where the value of the temperature at the exit of the collector:

$$
\begin{gathered}
T_{2}=T_{e}+\varphi_{0} \frac{E_{i}}{\lambda_{i}}\left[1-\exp \left(-\frac{\lambda_{i}}{E_{i}} \cdot \frac{\ell . L}{\rho . c_{p} \cdot q_{v}\left(1+\frac{\lambda_{i}}{E_{i}} \cdot \frac{2 e}{\lambda \cdot N u}\right)}\right)\right] \\
\Delta T=\varphi_{0} \frac{E_{i}}{\lambda_{i}}\left[1-\exp \left(-\frac{A}{1+B}\right)\right]
\end{gathered}
$$

$\lambda_{i}$ : conductivity of the insulation $(\mathrm{w} /(\mathrm{m}))$.

With

$A=\frac{\lambda_{i} \cdot \ell \cdot L}{E_{i} \cdot \rho \cdot c_{p} \cdot q_{v}}, B=\frac{\lambda_{i}}{E_{i}} \cdot \frac{2 e}{\lambda \cdot N u}$

When the insulation is perfect $\frac{\lambda_{i}}{E_{i}} \rightarrow 0$, and we fall back on the equation (12).

Finally, we obtain the performance of the flat air solar collector by the formula which equals the ratio between the two real powers and which supplied by the sun radiation:

$$
\begin{gathered}
\eta=\frac{\rho \cdot c_{p} \cdot q_{v}\left(T_{2}-T_{1}\right)}{\varphi_{0} \cdot \ell \cdot L} \\
\eta=\frac{\rho \cdot c_{p} \cdot q_{v} E_{i}}{\lambda_{i} \cdot \ell \cdot L}\left[1-\exp \left(-\frac{\lambda_{i}}{E_{i}} \cdot \frac{\ell \cdot L}{\rho \cdot c_{p} \cdot q_{v}\left(1+\frac{\lambda_{i}}{E_{i}} \cdot \frac{2 e}{\lambda \cdot N u}\right)}\right)\right]
\end{gathered}
$$

Ask

$$
1 / A=\frac{\rho \cdot c_{p} \cdot q_{v} E_{i}}{\lambda_{i} \cdot \ell \cdot L}
$$

$E_{i}$ : thickness of the insulation (m). $e:$ the thickness $(\mathrm{m})$.

$$
\eta=\frac{1}{A}\left[1-\exp \left(-\frac{A}{1+B}\right)\right]
$$

\section{Results and discussion}

\subsection{Mesh}

A mesh is a partition of space or a domain into elementary cells. To be usable for numerical simulation, the meshes must represent the geometry well enough, comprise enough elements to calculate precisely, in our model we used an unstructured mesh because of the complexity of the geometry of the flat air solar collector. The number of elements is 22,596 and the number of nodes is 122,606 .

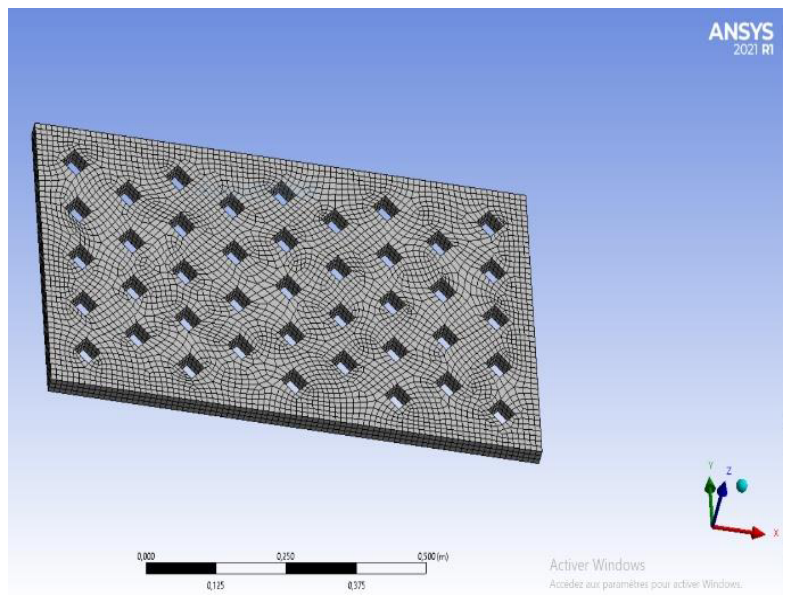

Fig. 2. 3D mesh of Solar Flat Plate Collector.

\subsection{Temperatures field}

The heat transfer mode between the absorber and the air is convection. The first layer of air near the absorber begins to warm up and goes mixed with the layer of secondary air due to obstacles and heat transfer due to conduction and convection, to improve heat transfer between the absorber and the air we have placed square obstacles to increase the flow path and create large areas of significant turbulence.

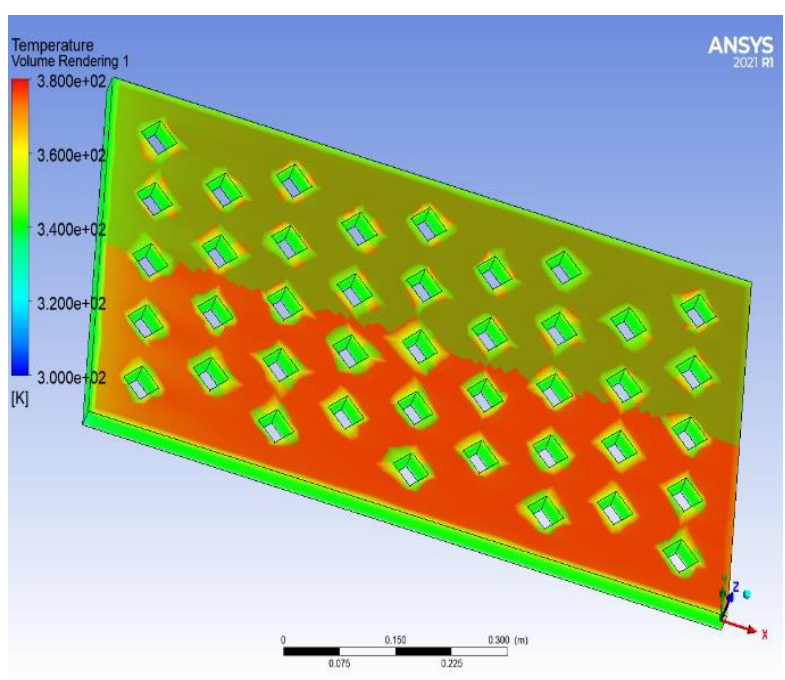

Fig. 3. Temperatures Field for the collector.

\subsection{The velocity vector $V$}

Figures 4 and 5 show the movement of air in the fluid stream of the flat air solar collector, the speed at the entry is similar until the arrival at the first row of obstacles or the speed increases more than $100 \%$ between the obstacles which means an increase in turbulence is the heat transfer between the absorber and the air. 


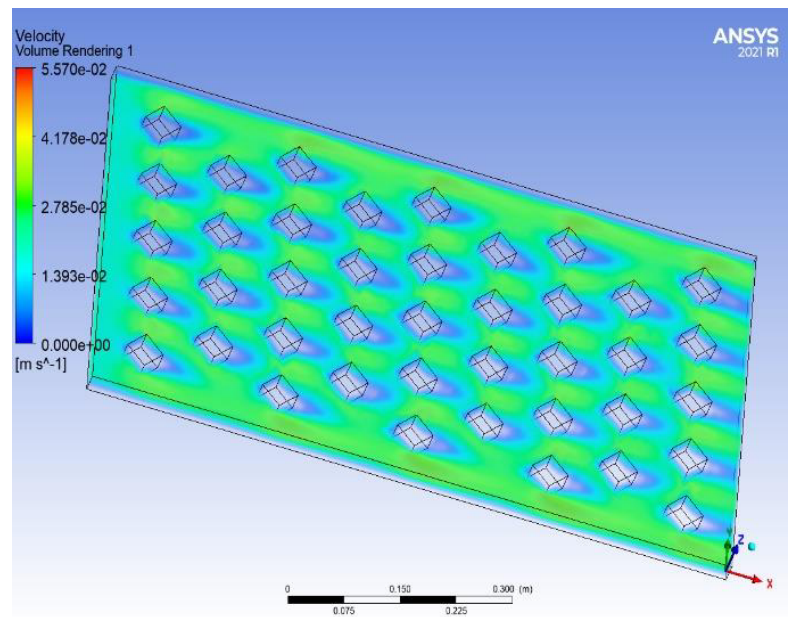

Fig. 4. Velocity distribution.

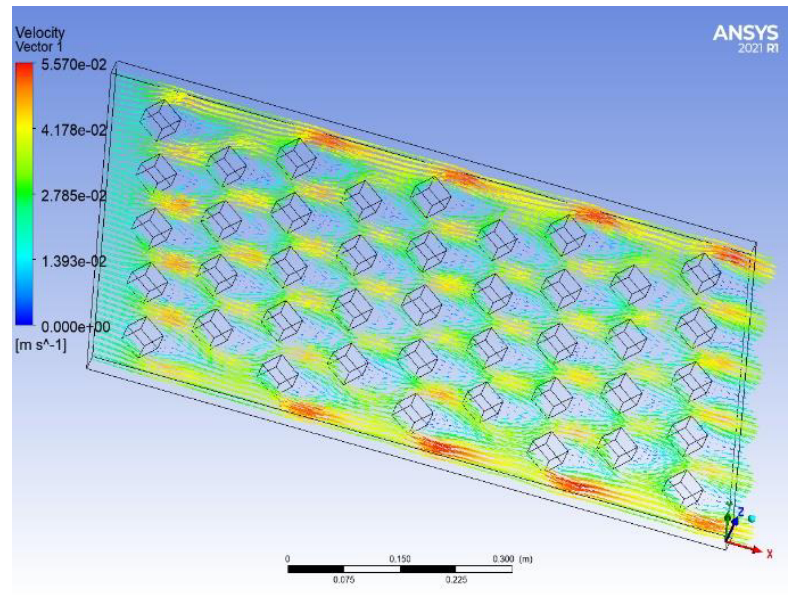

Fig. 5. Velocity vector.

\subsection{Turbulence field}

Figures 6 and 7 show the distribution of the turbulent kinetic energy $(\mathrm{k})$ and the turbulent vortex dissipation ( $\varepsilon)$ on the fluid stream of the flat air solar collector, the field of these energies appears in all the surface of the solar collector, we notice that there is a great increase in this energy close to the obstacles, but the turbulence diminishes when one moves away from the obstacles.

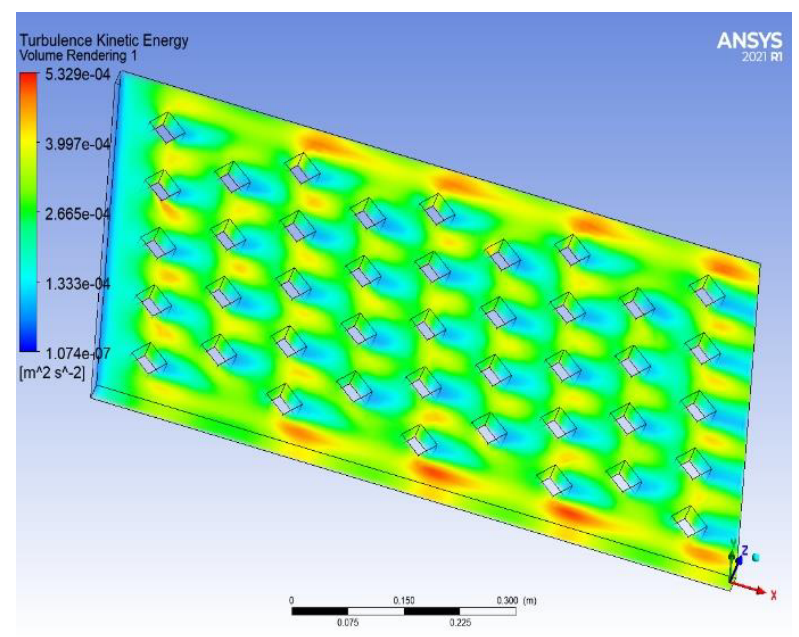

Fig. 6. Turbulent kinetic energy (k).

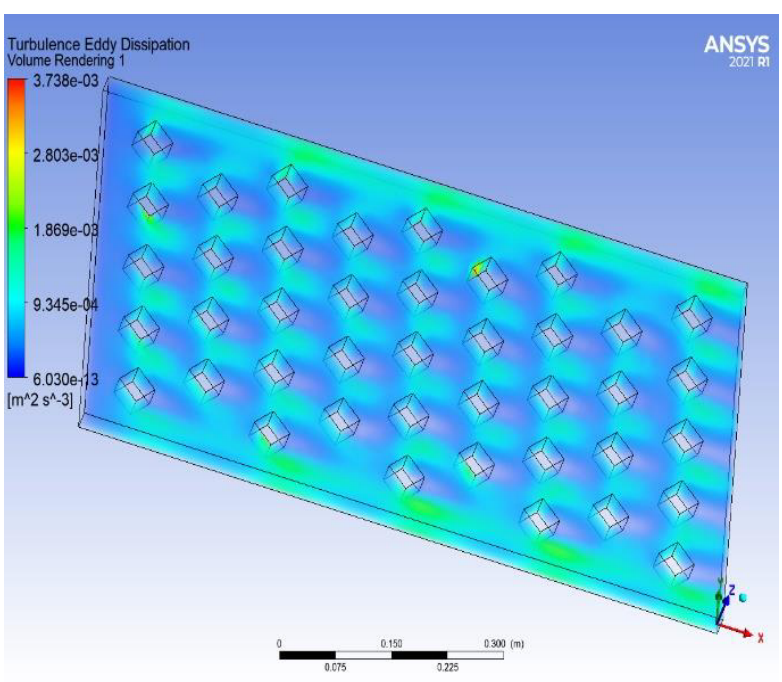

Fig. 7. Turbulent eddy dissipation $(\varepsilon)$.

\subsection{The Nusselt number and friction factor versus Reynolds number}

The study of a turbulent flow being much more difficult and complex, we seek more to determine the empirical correlations. For a fully developed turbulent flow in a smooth channel, the local Nusselt number can be obtained from the Dittus - Boelter equation [11].

$$
N u=0,023 R e^{4 / 5} \operatorname{Pr}^{0.4}
$$

$R e \geq 10000$

Petukhov [12] has developed a correlation for smooth surface finish that encompasses a wide range of Reynolds numbers and is presented as the friction factor as follows:

$$
f=(0,790 \ln R e-1,64)^{-2}
$$

$3000 \lesssim R e \lesssim 5 \times 10^{6}$

The flow Reynolds number, $R e$ is calculated as

$$
R e=\rho \bar{U} D_{h} / \mu
$$

The hydraulic diameter of the channel, $D_{h}$ is calculated as

$$
D_{h}=2 H W /(H+W)
$$

we made a study of local Nusselt number and friction factor as a function of different Reynolds number between (10500 up to 16500), we notice that the local nusselt number increases with the increase in reynolds number, for the friction factor decreases with increasing reynolds number. 


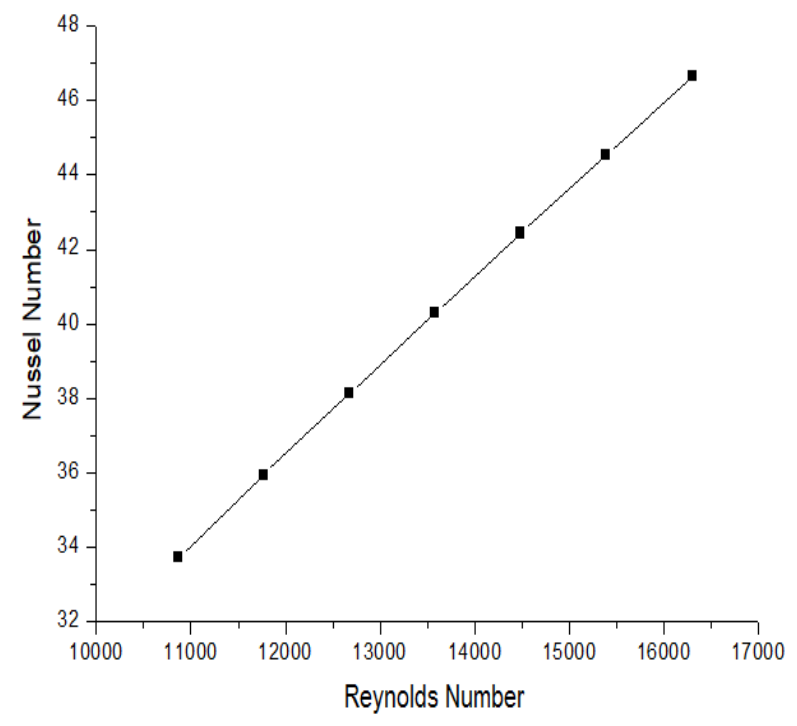

Fig. 8. The local Nusselt number versus Reynolds number.

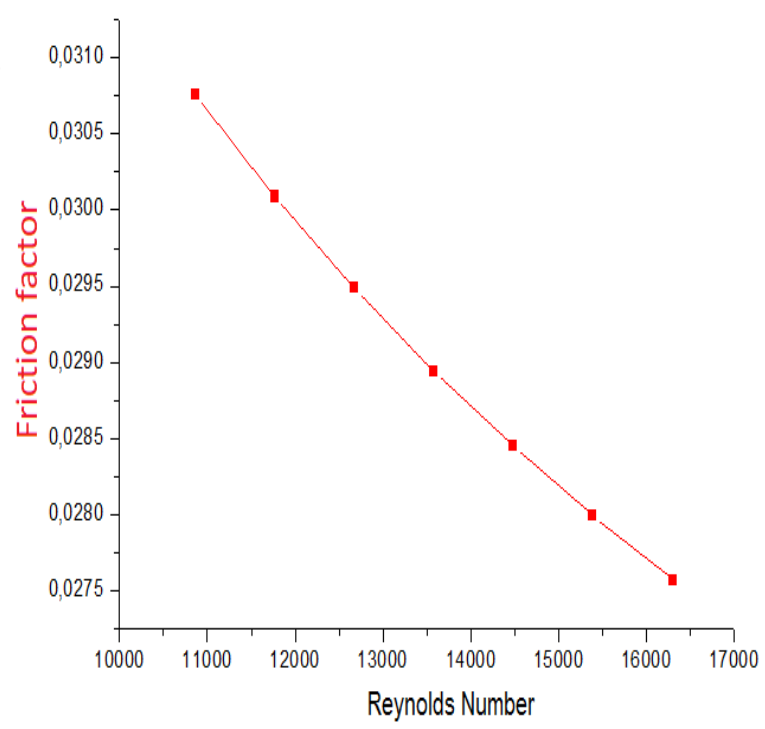

Fig. 9. The friction factor versus Reynolds number.

\section{Conclusions}

To increase the efficiency of the flat air solar collector we have added square obstacles to increase the efficiency, so we have a very important path of the air flow in the fluid vein of the flat air solar collector and important ones zone of turbulence close to obstacles square. We also notice an increase in the speed between the obstacles due to the section narrowing. we made this placement of obstacles square to reduce the dead zones downstream of the obstacles. we also notice an increase in the local Nusselt number and decrease in the friction factor if the Reynolds number increases.

\section{References}

1. M. A. Bernier and al, Thermal performance representation and testing of air solar collectors, Annales de chimie et de physique, Journal of Solar Energy Engineering, MAY 1988, Vol. 110/75
2. Z. Sari Hassoun and al, Etude expérimentale d'un capteur solaire plan à air doté de concentrateurs, 4ème Conférence Internationale des Energies Renouvelables

3. Ole Arborg, Air solar collectors, Annales de chimie et de physique, International Journal of Ambient Energy, , 3:3, 147-152, DOI: 10.1080/01430750.1982.9675842

4. Andrei-Stelian Bejan and al, Air solar collectors in building use - A review, E3S Web of Conferences 32, 01003 (2018)

5. T. Letz and al, Etude théorique et expérimentale d'un capteur solaire plan à air en régime dynamique, Revue Phys. Appl. 21 (1986) 727-734, novembre 1986

6. Ioan Luminosu and al, Thermodynamic analysis of an air solar collector, Int. J. Exergy, Vol. 2, No. 4, 2005

7. M. Zedairia and al, Effet des paramètres géométriques sur les performances thermiques des capteurs solaires plans à air, Journées d'Etudes Nationales de Mécanique, JENM'2015

8. S. Oudjedi, Etude paramétrique d'un capteur solaire plan à air destiné au séchage (Partie : 2), Revue des Energies Renouvelables SMSTS'08 Alger (2008) 255 - 266

9. A. Moummi, Etude globale et locale du rôle de la géométrie dans l'optimisation des capteurs solaires plans à air, In Phd thesis, université de Valenciennes et du Hainaut cambresis, France, 1994

10. M.A. Amraoui and al, Three-dimensional analysis of air flow in a flat plate solar collector, In Periodica polytechnica mechanical engineering, 2018

11. Winterton, R. H. S., Int. J. Heat Mass Transfer, 41, 809, 1998

12. B. S. Petukhov, in T. F. Irvine and J. P. Hartnett, Eds., Advances in Heat Transfer, Vol. 6, Academic Press, New York, 1970 